\title{
THE AGGLUTINATION OF AUTOCLAVED HEMOLYTIC STREPTO- COCCI BY SERUM FROM PATIENTS WITH RHEUMATIC FEVER AND OTHER CONDITIONS ${ }^{1}$
}

\author{
By SUNG J. LIAO ${ }^{2}$ \\ (From the Section of Preventive Medicine, Yale University School of Medicine, New Haven)
}

(Received for publication September 20, 1948)

Thulin (1-3) has recently reported an agglutination test, using human serum and hemolytic streptococci which had been treated at a high temperature. He found that in human sera the agglutination titers were significantly higher in samples from patients with rheumatic fever and with rheumatoid arthritis than in others and that the titers observed in both diseases were similar. This test would seem to offer an unusually simple technique for the measurement of antibodies which occur in active streptococcal diseases and in rheumatoid arthritis. Many streptococcal agglutination tests have been described and proposed in the past, but the principle of subjecting the bacterial suspension to a temperature of $120^{\circ} \mathrm{C}$ prior to its use as an agglutinogen (4), is a new suggestion insofar as its clinical application for the study of streptococcal diseases is concerned; for this reason alone it has seemed to deserve further investigation.

It is the purpose of this paper therefore to report confirmation of Thulin's observation that sera from patients with rheumatic fever and rheumatoid arthritis agglutinate autoclaved streptococci and to present the results of further investigations utilizing this technique.

\section{MATERIALS AND METHODS}

1) Rreparation of bacterial suspension. The hemolytic streptococcus ${ }^{3}$ used throughout the present work was a strain of Group A Type 4. Cultures were made with beef heart infusion broth containing either $0.5 \%$ calf serum or $1 \%$ glucose; after incubation at $37^{\circ} \mathrm{C}$ for 15 to 18 hours, the bacterial cells were collected by centrifugation and washed once with phosphate buffer solution $(0.01 \mathrm{M})$ at $\mathrm{pH}$ 7.8. The cells were then resuspended in the buffer and autoclaved at a temperature of

1 Aided by a grant from the Life Insurance Medical Research Fund.

2 Milbank Memorial Fund Fellow.

3 The term "hemolytic streptococcus" throughout this paper refers to the Lancefield Group A beta-hemolytic streptococcus, unless stated otherwise. $120^{\circ} \mathrm{C}$ for two hours. The heat-treated cells were then washed twice with the buffer ( $\mathrm{pH} 7.8)$. Finally, a heavy suspension of the autoclaved bacteria was made in a small volume of physiological saline, buffered with $0.01 \mathrm{M}$ phosphate to $\mathrm{pH} 7$. Tests done with unbuffered saline prepared from laboratory-distilled water, which was found to have a $\mathrm{pH}$ of about 5 to 6 , gave non-specific agglutination.

For the agglutination test, the bacterial suspension was diluted to a concentration of about 100 million organisms per milliliter by comparison with a barium sulphate standard, containing a third of the strength of the No. 1 tube of the Brown's standard $(5,6)$. The undiluted bacterial suspension was usually not kept longer than one week in the refrigerator at a temperature of $4^{\circ} \mathrm{C}$. Diluted suspensions were freshly made for each test from the stock.

2) Serum. Samples of serum were obtained from patients suffering from rheumatic fever of varying severity and at different stages of their illness; from patients with scarlet fever or other bacteriologically proven streptococcal diseases taken during active and convalescent stages of their illness; from patients affected by rheumatoid arthritis, taken at various stages of the disease; from individuals with a wide variety of ailments other than the above three; and from "normal" subjects.4 All the samples of serum were stored at $-17^{\circ} \mathrm{C}$ and were not heated before being tested.

3) The agglutination technique. Serial two-fold dilutions of serum were made with buffered saline ( $\mathrm{pH} 7$ ), starting from 1:20. To $0.2 \mathrm{ml}$ of serum dilution in each tube an equal volume of the bacterial suspension was added. Therefore, the final dilutions of each serum tested ranged from $1: 40$.

After the addition of the cells to the serum, the tubes were shaken, incubated in a $52^{\circ} \mathrm{C}$ waterbath for two hours and left in the refrigerator at $4^{\circ} \mathrm{C}$ for a period of 15 to 18 hours. A longer time in the refrigerator tended to give rise to excessively high titers, while too short a period resulted in low titers. When the test was read, the individual tubes were gently shaken and then read

4 The serum samples were collected and generously made available by Dr. Robert W. Quinn from the patients in the Grace-New Haven Community Hospital and Dispensary Clinics, New Haven, Conn., the U. S. Naval Hospital, St. Albans, L. I., St. Francis Sanatorium for Cardiac Children, Roselyn, L. I., the Children's Center, New Haven, Conn., and Southbury Training Center, Southbury, Conn. 
against a black background, without the aid of a hand lens. The presence of sandy granules which were not broken into a homogeneous suspension by the shaking was considered as definite agglutination. The final dilution of the serum in the last tube of the series which showed definite agglutination was taken as the agglutination titer of the sample.

4) Calculations. In this agglutination test, two-fold dilutions of serum were used and the final dilution of serum was adopted for the agglutination titer of the sample. This serial two-fold dilution of serum forms a geometric series with a common ratio of $1: 2$. To obtain a geometric mean from numericals of the dilutions is not too easy a job. If it could be converted into an arithmetic series, the task would then not be difficult. The series of dilutions of serum starts with $1: 40$. Here $40=20 \times 2^{1}$. The next tube contains a dilution of serum of $1: 80$, where $80=20 \times 2^{2}$. The third tube contains a
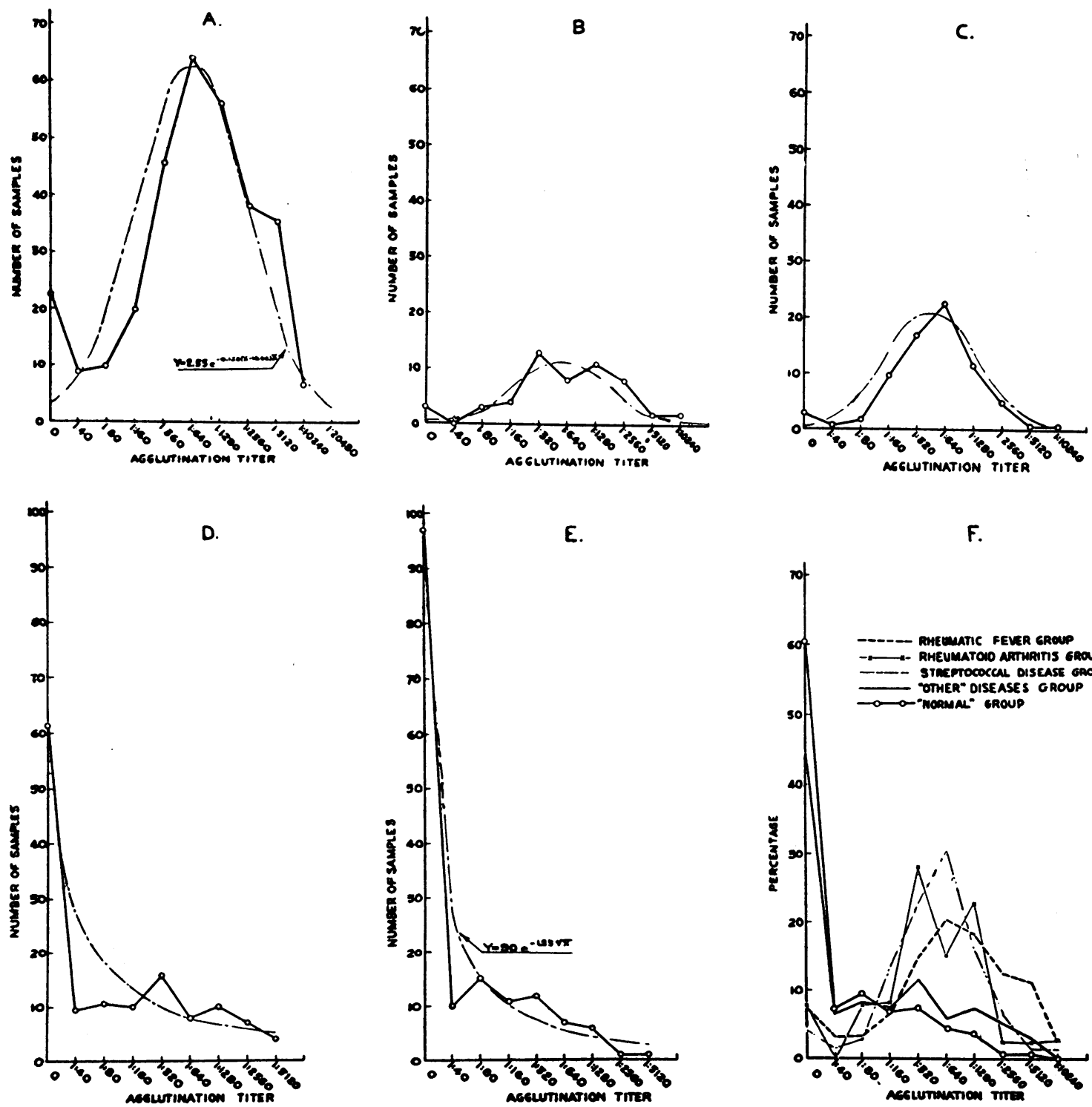

F.

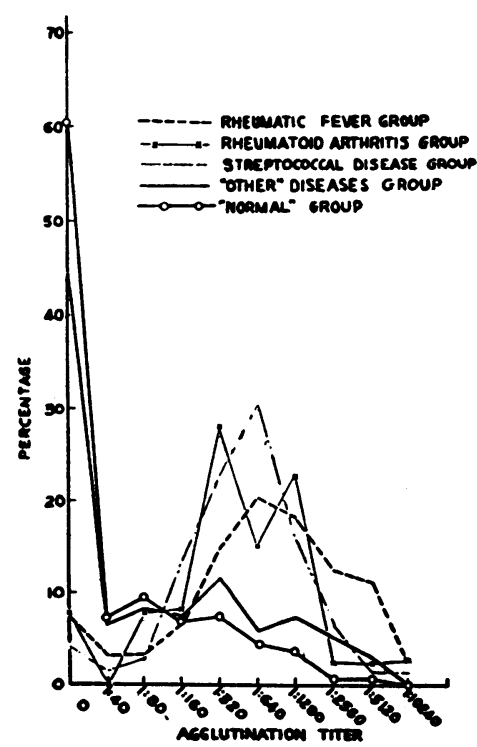

Fig. 1. Distribution of Agglutination Titers of the Five Groups of Human Serum

A. Serum from patients with rheumatic fever. (311 samples, mean titer $1: 646$.)

B. Serum from patients with rheumatoid arthritis. (50 samples, mean titer $1: 614$.)

C. Serum from patients with "streptococcal diseases." (75 samples, mean titer 1:474.)

D. Serum from patients with "other" diseases. (137 samples, mean titer 1:95.)

E. Serum from "normal" subjects. (160 'samples, mean titer $1: 49$.)

F. Percentage distribution of the five groups. 

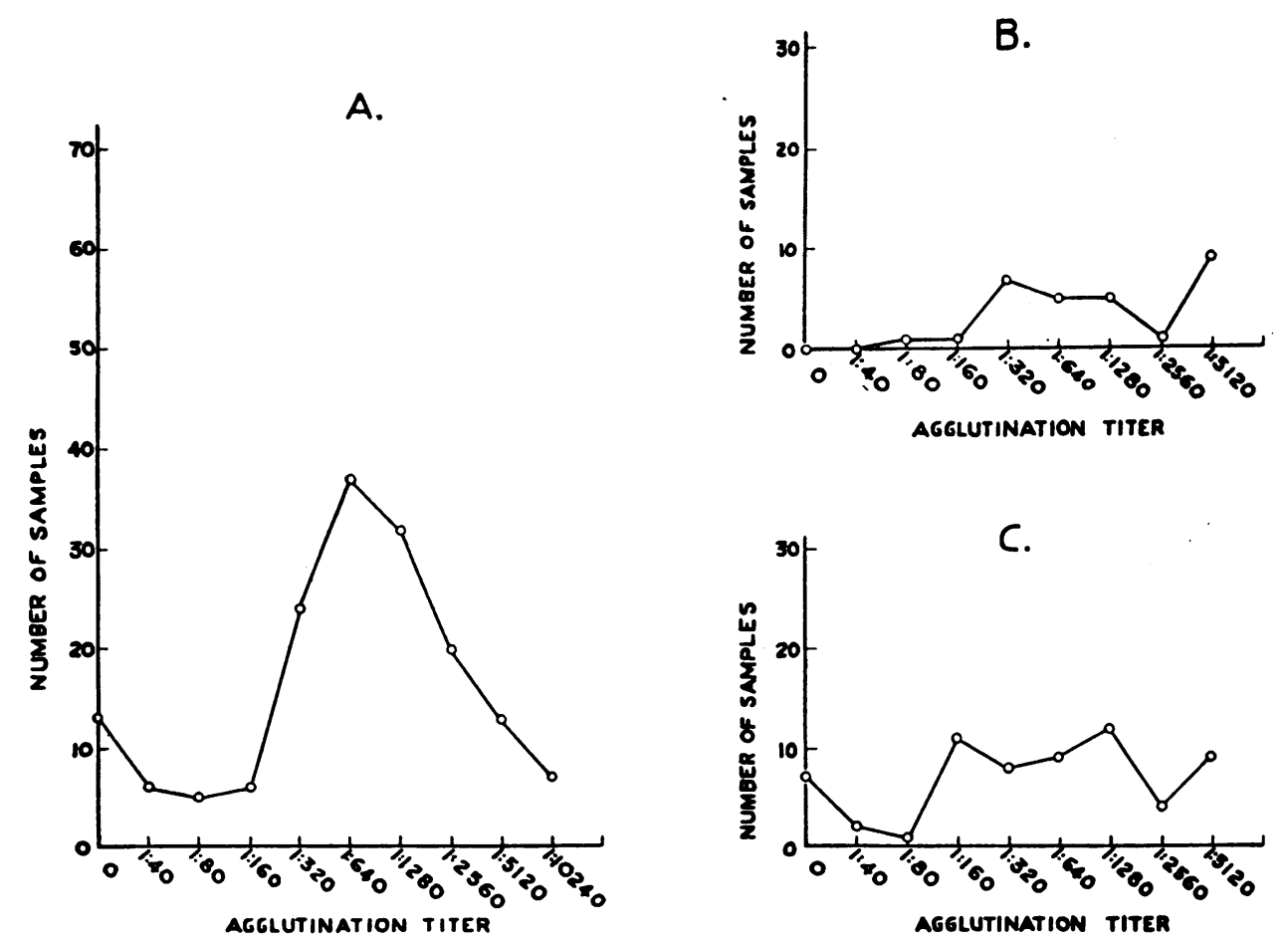

Fig. 2. Frequency Distribution of Agglutination Titers of Serum from Rheumatic Fever Patients

A. Active. (163 samples, mean titer 1:640.)

B. Active subsiding. (29 samples, mean titer $1: 1084$.)

C. Inactive. (63 samples, mean titer $1: 456$.)

dilution of $1: 160$, where $160=20 \times 2^{3}$. And so on. The ninth tube contains a dilution of $1: 10240$, where 10240 $=20 \times 2^{\circ}$. This series may, then, be coded with the first tube $(1: 40)$ as 1 , second tube $(1: 80)$ as $2, \ldots$ the ninth tube $(1: 10240)$ as 9 , and with a negative reaction as 0 (Table I). Thus, the mean, the standard deviation, and the standard error of a group of serum may be calculated as usual. The $t$-test is used to compare the differences between two groups.

For converting the code of the mean into the original series, the following procedure may be taken. Taking the first group of serum as an example, the mean was calculated to be 5.01 in terms of the code. 5.01 lies between 5 and 6 . 5 corresponds to $1: 20 \times 2^{5}$. 5.01 should correspond to $1: 20 \times 2^{5.02}$, or $1: 645$.

\section{RESULTS}

The first group consisted of 311 samples of serum obtained from 193 patients with rheumatic fever representing wide variations in severity and duration of activity of the disease. Only 23 of the 311 (7.4\%) failed to show any agglutination (negative), and $269(86.5 \%)$ showed agglutination titers of $1: 160$ or higher. The geometric mean titer of the group as a whole was $1: 645$ (or 5.01, in terms of the code, with a standard deviation of 2.26 and standard error of 0.128) (Figure 1-A).

Sera from some of the rheumatic fever patients were further studied to determine the relation of the agglutination titer to the stage of the illness. Of the 311 samples of sera (charted in Figure 1-A), 49 were obtained from rheumatic fever patients whose detailed histories were not definitely known. Since the stage of their disease could not be determined accurately they were excluded from this analysis. One hundred and sixty-three samples were taken during the active phase of their illness and of these, $13(8 \%)$ were negative and $139(85.3 \%)$ had a titer of $1: 160$ or higher, with a mean agglutination titer of $1: 640$ (or 5.0, in terms of the code, with a standard deviation of 2.29 and a standard error of 0.182 ). It is noteworthy that the specimens of serum from ten of the 13 negative reactors were obtained within one week of the onset of their disease (Figure 2-A). 
Twenty-nine samples were obtained from rheumatic fever patients when the activity of the disease was considered to be subsiding. None of these was negative and the agglutination titer of 28 samples was $1: 160$ or higher, with a mean titer of $1: 1084$ (or 5.76 , in terms of the code, with a standard deviation of 3.01 and standard error of 0.558 ) (Figure 2-B).

Of 63 specimens of sera obtained from rheumatic fever patients during the inactive phase of their illness, seven $(11.1 \%)$ were negative and 53 $(84.2 \%)$ had a titer of $1: 160$ or higher with a mean titer of $1: 456$ (or 4.51 , in terms of the code,

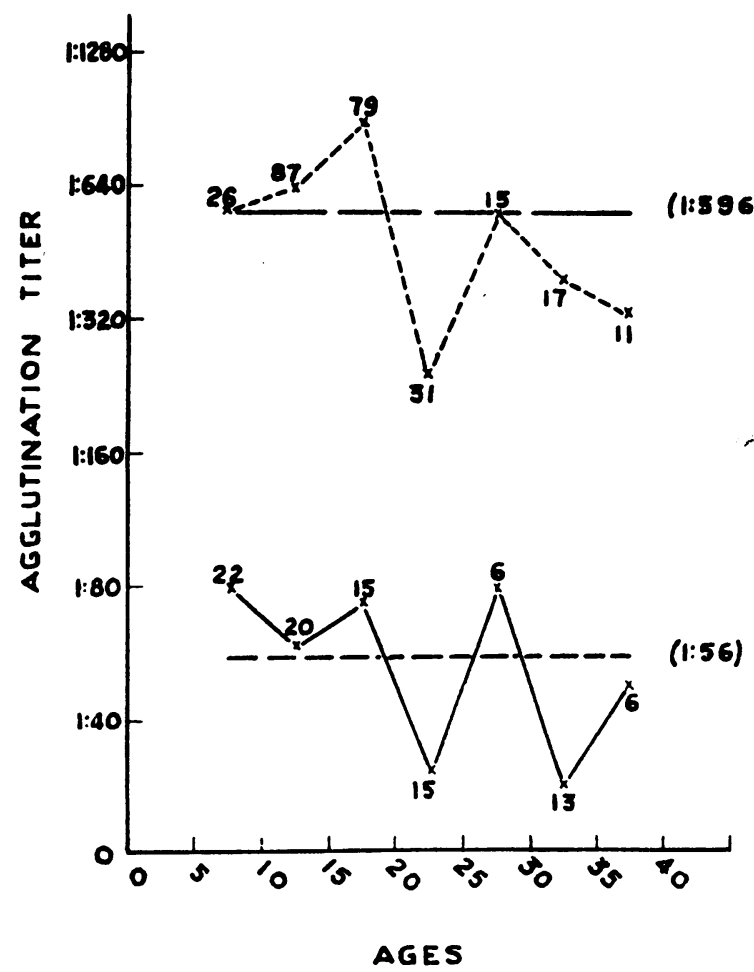

Fig. 3. Comparison of Mean Agglutination Titers of Rheumatic Fever Patients at Various Ages with Those of "Normals" of the Sample Age Group

In the top graph, the dotted line and crosses represent the distribution of mean agglutination titers of the rheumatic fever group at various ages; and the horizontal broken line, the grand mean titer of the rheumatic fever group (1:596 for a total of 266 samples).

In the lower graph, the lines and crosses represent the distribution of mean agglutination titers of the "normal" group at various ages; and the horizontal broken line, the grand mean titer of the "normal" group (1:56 for a total of 97 samples).

The numericals at each point indicate the number of samples examined at that particular age group.

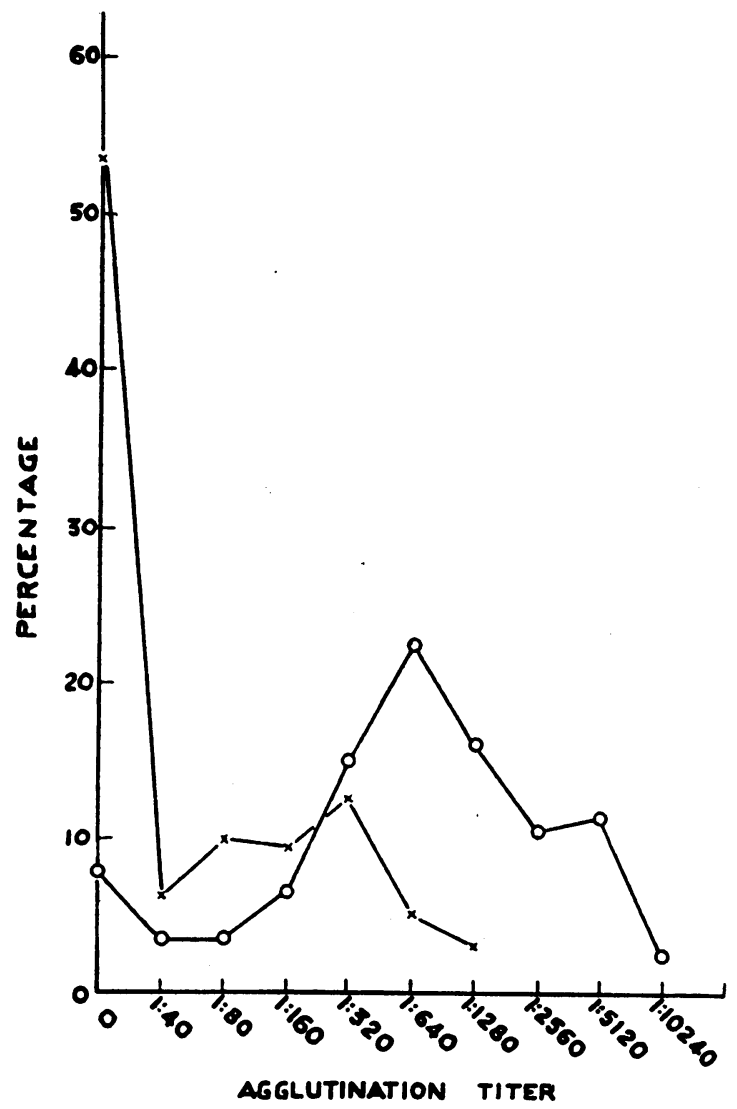

Fig. 4. Percentage Distribution of Agglutination Titers of Serum from Rheumatic Fever Patients and from "Normal" Subjects of Ages Between Five AND 40

The circles represent rheumatic fever patients; the crosses, "normal" subjects.

with a standard deviation of 2.42 , and a standard error of 0.305 ) (Figure 2-C).

There were seven samples of serum from patients with a diagnosis of possible rheumatic fever; and of these one was negative, and six had titer above $1: 160$. The mean agglutination titer was $1: 640$ (or 5.0 in terms of the code, with a standard deviation of 1.73 , and standard error of 0.655 ).

From our data, the ages of 268 rheumatic fever patients were definitely known. Of these, 266 fell between the ages of five and 40 . The mean agglutination titers of serum samples grouped in fiveyear periods were computed. The mean agglutination titer of the whole group was estimated to be $1: 596$. Of the same age group (five to 40 ), 97 samples from normal controls were recorded. They were analyzed in the same manner. The 
mean agglutination titer of this group was $1: 56$. The difference between the mean agglutination titers of these two groups of population at the same ages was statistically significant (Figure 3 ). The percentage distributions of agglutination titers of these two groups were essentially the same as the original corresponding group (Figure 4).

Serial bleedings of three or more samples from each individual were obtained from 32 patients of the rheumatic fever group; they represented periods of observation varying from 21 to 245 days. In general, the agglutination reaction was negative in the first few days after the onset of the acute ill- ness; thereafter the titer rose fairly rapidly to a level of $1: 320$ or higher during the active stage; and during the convalescent phases, it usually remained at this high level. In the few instances when the agglutination titer fell, the level, nevertheless, remained much higher than the mean titers of the control groups. Readings from three representative patients are shown in Figure 5.

Of the second group, comprising 50 samples of sera from 38 patients suffering from rheumatoid arthritis, three $(6 \%)$ were negative and $44(88 \%)$ had titers of $1: 160$ or higher. The mean titer for the group was $1: 614$ (or 4.76 in terms of the code,

PATIENT WW

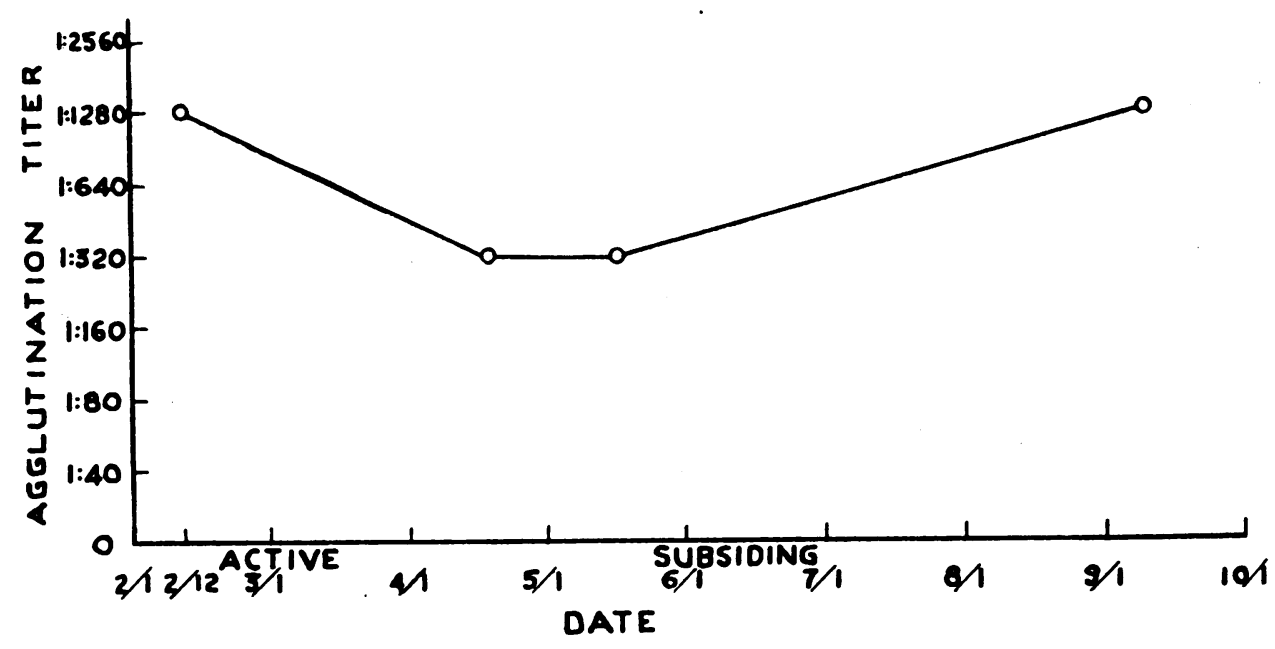

PATIENT SE

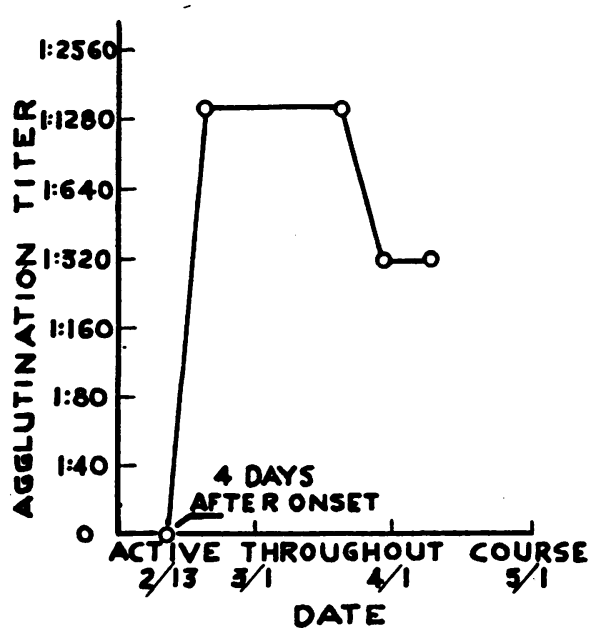

PATIENT PC

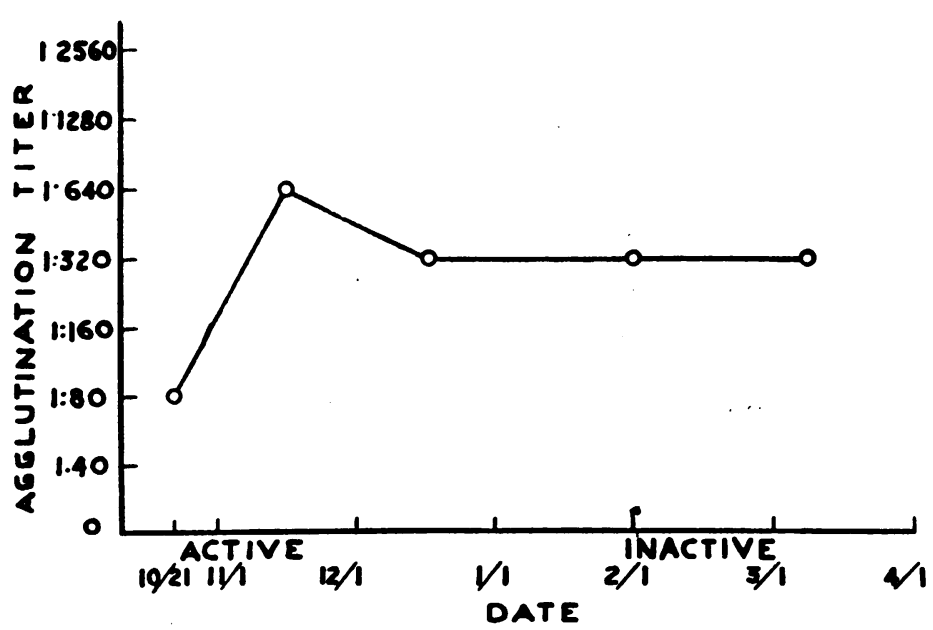

Fig. 5. The Agglutination Titer of Serum from Three Patients with Rheumatic Fever as Correlated to the Clinical Course of the Disease 
TABLE I

The distribution of the agglutination titers of the five groups of serum examined

\begin{tabular}{|c|c|c|c|c|c|c|c|c|c|c|c|}
\hline \multirow{2}{*}{ Titer } & \multirow{2}{*}{ Code } & \multicolumn{2}{|c|}{$\begin{array}{c}\text { Rheumatic } \\
\text { fever }\end{array}$} & \multicolumn{2}{|c|}{$\begin{array}{c}\text { Rheumatoid } \\
\text { arthritis }\end{array}$} & \multicolumn{2}{|c|}{$\begin{array}{l}\text { Streptococcal } \\
\text { diseases }\end{array}$} & \multicolumn{2}{|c|}{$\begin{array}{l}\text { "Other" } \\
\text { diseases }\end{array}$} & \multicolumn{2}{|c|}{$\begin{array}{l}\text { "Normal" } \\
\text { subjects }\end{array}$} \\
\hline & & No. & $\%$ & No. & $\%$ & No. & $\%$ & No. & $\%$ & No. & $\%$ \\
\hline $\begin{array}{l}\text { Negative } \\
1: 40 \\
1: 80 \\
1: 160 \\
1: 320 \\
1: 640 \\
1: 1280 \\
1: 2560 \\
1: 5120 \\
1: 10240\end{array}$ & $\begin{array}{l}0 \\
1 \\
2 \\
3 \\
4 \\
5 \\
6 \\
7 \\
8 \\
9\end{array}$ & $\begin{array}{r}23 \\
9 \\
10 \\
20 \\
46 \\
64 \\
57 \\
39 \\
36 \\
7\end{array}$ & $\begin{array}{r}7.4 \\
2.9 \\
3.2 \\
6.4 \\
14.8 \\
20.6 \\
18.4 \\
12.6 \\
11.5 \\
2.2\end{array}$ & $\begin{array}{r}3 \\
0 \\
3 \\
4 \\
43 \\
13 \\
8 \\
11 \\
4 \\
2 \\
2\end{array}$ & $\begin{array}{r}6 \\
0 \\
6 \\
8 \\
26 \\
16 \\
22 \\
8 \\
4 \\
4\end{array}$ & $\begin{array}{r}3 \\
1 \\
2 \\
10 \\
17 \\
23 \\
12 \\
5 \\
1 \\
1\end{array}$ & $\begin{array}{r}4.0 \\
1.3 \\
2.7 \\
13.4 \\
22.6 \\
30.6 \\
16.0 \\
6.7 \\
1.3 \\
1.3\end{array}$ & $\begin{array}{r}61 \\
10 \\
11 \\
10 \\
16 \\
8 \\
10 \\
7 \\
4 \\
0\end{array}$ & $\begin{array}{r}44.5 \\
7.3 \\
8.0 \\
7.3 \\
11.6 \\
5.8 \\
7.3 \\
5.1 \\
2.9 \\
0\end{array}$ & $\begin{array}{r}97 \\
10 \\
15 \\
11 \\
12 \\
7 \\
6 \\
1 \\
1 \\
0\end{array}$ & $\begin{array}{r}60.6 \\
6.2 \\
9.4 \\
6.9 \\
7.5 \\
4.4 \\
3.8 \\
0.6 \\
0.6 \\
0\end{array}$ \\
\hline Total for each group & & 311 & 100.0 & 50 & 100 & 75 & 99.9 & 137 & 99.8 & 160 & 100 \\
\hline $\begin{array}{l}\text { Mean titer for each } \\
\text { group }\end{array}$ & & \multicolumn{2}{|c|}{$1: 645$} & \multicolumn{2}{|c|}{$1: 542$} & \multicolumn{2}{|c|}{$1: 472$} & \multicolumn{2}{|c|}{$1: 95$} & \multicolumn{2}{|c|}{$1: 49$} \\
\hline
\end{tabular}

with a standard deviation of 1.68 and standard error of 0.194) (Figure 1-B).

The third group of sera comprised 75 samples from 65 patients who were either in the active or convalescent stage of scarlet fever or other bacteriologically proven streptococcal infections. Three $(4 \%)$ of the 75 samples collected were negative and $69(92 \%)$ showed a titer of $1: 160$ or over, with a mean titer of $1: 472$ for this group (or 4.56 in terms of the code, with a standard deviation of 1.68 and standard error of 0.194 ) (Figure 1-C).

The fourth group (one of the two control groups) of sera included 137 specimens of serum obtained from 133 patients in the Grace-New Haven Community Hospital with infectious and non-infectious diseases other than those given above. Of the 137 sera in this group, 61 (44.5\%) gave negative results and $55(40.2 \%)$ had an agglutination titer of $1: 160$ or higher. The mean agglutination titer was 1:95 (or 2.24 in terms of the code, with a standard deviation of 2.53 and a standard error of 0.216) (Figure 1-D).

In this fourth group, 11 patients suffering from lobar pneumonia were also included. The sera of nine of them gave negative results and two demonstrated an agglutination titer of $1: 80$ with a mean titer of $1: 17$. This fourth group also included 14 patients with tonsillitis in whom definite bacteriological proof for hemolytic streptococcus as the causative organism was lacking. Among these 14 the sera of three gave a negative reaction, while those of ten gave agglutination titers of $1: 160$ or higher. The mean titer of the 14 was 1:290 (or 3.86 in terms of the code, with a standard deviation of 2.50 and standard error of 0.664 ). After the exclusion of these 14 patients, the mean agglutination titer of the fourth group became $1: 83$ (or 2.06, with a standard deviation of 2.48 and a standard error of 0.223 ).

The fifth group (the other control group) comprised sera from "normal" subjects, and included apparently healthy subjects, surgical patients such as those with simple fractures or hernias, and those admitted for routine tonsillectomy and adenoidectomy. From 142 "normal" s subjects, 160 samples of sera were obtained. Of the 160,97 $(60.6 \%)$ were negative and $38(23.8 \%)$ showed a titer of $1: 160$ or higher. The mean agglutination titer for the group was $1: 49$ (or 1.29, in terms of the code, with a standard deviation of 1.94 and standard error of 0.153 ) (Figure 1-E).

A comparison was made of the above five groups with regard to the percentage distributions of their agglutination titers. This is illustrated in Figure 1-F.

No special effort was made to determine the experimental error of this particular agglutination test. However, from repeated tests on 25 samples of serum (two tests on each sample at differ-

5 The word "normal" is used in this paper for convenience as the designation for this heterogeneous group of subjects who were apparently healthy or had no obvious infectious diseases. 
ent times and with different preparations of the bacterial suspension), the mean difference of agglutination titers was found to be less than twofold. Therefore, a four-fold difference of the agglutination titers may be considered significant.

\section{DISCUSSION}

Significance of finding. From the observations made, there was no statistically significant difference of the mean agglutination titers among the first three groups, viz., rheumatic fever, rheumatoid arthritis and streptococcal diseases. The differences between the mean titers of each of these three groups and the fourth (or patients suffering from diseases other than the above three) were highly significant statistically. Likewise, the differences between the mean titers of each of the above first three and the last group (composing "normal" subjects) also were significant. Though a statistically significant difference between the two control groups (i.e., the fourth and the fifth) was demonstrated, this might be explained by the inclusion of patients suffering from tonsillitis and other similar conditions where definite bacteriological proof of causation by the hemolytic streptococcus was not obtained. The agglutination titers of the sera of these tonsillitis patients were, on the average, higher than those of the sera of other patients. The result of the fourth group as a whole might thus be influenced to some extent. However, the exclusion of these 14 patients did not significantly alter the mean agglutination titer of the fourth group. The differences between the fourth group after exclusion of these patients and the fifth group remained still significant. Among other causes, it is conceivable that an anamnestic reaction caused by the present illness on previous experiences with the streptococcus, known or unknown, might also contribute to the slightly higher mean titer of the fourth group. Therefore, this difference between the two control groups might not be taken too seriously. The frequency distribution curves of the agglutination titers of these two control groups were essentially the same (Figure $1, \mathrm{D}$ and $\mathrm{E}$ ). Those of the first three groups followed the pattern of the normal distribution curve (Figure 1).

Because the mean agglutination titers of the control groups were below $1: 100$, and those of the three test groups were above $1: 320$, it has seemed reasonable to set the tentative line of demarcation between the control and the test groups at the level of $1: 160$. Therefore, if this test is to be used for clinical diagnostic purposes and when rheumatic fever is suspected, an agglutination titer of the patient's serum against autoclaved hemolytic streptococcus above 1: 160 may be considered suggestive. From the estimation made by means of an empirical equation, $y=2.55 e^{-0.128 x(x-10.02)}$ which was constructed from the data of the rheumatic fever group, the chances that the serum sample from a rheumatic fever patient would show an agglutination titer of, or over, 1:160 were 85 times out of 100 . For the serum of a "normal" subject, the chances of being so were only about 20 times out of 100 , as estimated from an empirical equation, $y=90 e^{-1.25 \sqrt{x}}$ which was computed from our data. The estimate for the latter group was inevitably rather high, perhaps because the frequent occurrence of unrecognized infections of hemolytic streptococcus may give rise to an increased antibody titer. In the rheumatic fever group, a negative agglutination reaction, or a positive one with a low titer, might be explained by the fact that, at very early stages of the disease, the individual might not have elaborated enough antibodies against the "infection" to give a positive reaction with a high titer above the normal level. Moreover, there are always individual variations in the reaction to any antigenic stimulation. It is not to be expected, therefore, to observe a uniform narrow range of antibody titer. As is well known, for example, in the production of diphtheria antitoxin some horses are encountered which are refractory to diphtheria toxin or toxoid.

Rheumatic fever. Since rheumatic fever is mainly a disease of younger age groups, the question may be raised as to whether the age distribution of the rheumatic fever patients was sufficiently different from the control groups as to make a comparison impossible. As shown in Figure 3, the differences between the mean agglutination titers of the serum of these two groups of population at the same ages were statistically significant. Furthermore, the percentage distribution of agglutination titers of these two groups did not differ from their original corresponding groups. This serves as additional evidence that the agglutination titers were higher in rheumatic fever patients than in "normal" subjects. 
From the studies on serial samples taken from patients at various stages of rheumatic fever, a negative reaction was observed with sera obtained within a week of the onset of the disease and the agglutination titer subsequently rose fairly rapidly and thereafter remained elevated. Thulin (3) attributed this agglutination reaction to an " $\mathrm{O}$ antigen" in the hemolytic streptococci. He also observed that "the $\mathrm{O}$ agglutinins are acute antibodies which, as a rule, make their appearance in seven to 14 days after the onset," and "in chronic cases, ... the $\mathrm{O}$ agglutinins remain relatively unchanged." A negative reaction, therefore, does not exclude the presence of rheumatic fever particularly in the early stages, but a rise of the titer during the course of the disease is very suggestive. Repeated determinations at weekly intervals would appear to be indicated when the test is used as an aid in diagnosis. The degree to which sustained elevation of streptococcal agglutinins are maintained in rheumatic fever in possible contrast to the response in acute streptococcal disease is as yet unknown.

Rheumatoid arthritis. Extensive work has been done on agglutination reactions against hemolytic streptococcus with sera from patients suffering from rheumatoid arthritis. However, not many of the previous studies included numerous samples of sera from patients with rheumatic fever. The majority of them have shown higher values for rheumatoid arthritis and thus constituted a differential test between rheumatoid arthritis and rheumatic fever. The bacterial suspensions employed were either live cultures of streptococci or streptococcal suspensions killed at $56^{\circ} \mathrm{C}$. Because the methods used were so different, a comparison of the data of previous studies with the results of the present work cannot easily be made. Although Clawson et al. (7) and Goldie $(8,9)$ demonstrated no difference of agglutination titers between sera from rheumatoid arthritis and rheumatic fever patients, the bacterial suspensions used by the two groups of workers were different. The size of the population examined and the stage of disease when the samples were collected are among the important factors which contribute to the variations in antibody titer, as demonstrated by different investigators. Using autoclaved hemolytic streptococci, Thulin obtained higher agglutination titers in rheumatoid arthritis and rheumatic fever patients than in controls. In the series published in 1947 by him (2) 34 out of 43 of the "chronic polyarthritis" group showed agglutination titers of $1: 160$ or higher and none was negative. Of the rheumatic fever group, 13 of 16 showed agglutination titers of $1: 160$ or higher and none was negative; and of the control group, 114 of 117 were negative while not a single sample had a titer of $1: 160$ or higher. The following information was given in his latest monograph (3) : 54 patients with rheumatic fever were examined by him within three to six months after onset; $51.9 \%$ of them showed an agglutination titer of 1:160 or higher. Over half of each of 20 scarlet fever patients and of 20 patients with acute tonsillitis had agglutination titers of $1: 160$ or higher. Of 285 patients with rheumatoid arthritis, $51.6 \%$ gave titers of $1: 160$ or higher. Only $7.6 \%$ of the control serum showed agglutination titers of $1: 40$ or higher. Our observations, as noted above, agree well to these points.

From the present study, this agglutination test could not differentiate rheumatic fever from rheumatoid arthritis. Since the number of series of bleedings at various stages of illness obtained from patients suffering from rheumatoid arthritis was not large, it is rather difficult to make definite comment on the usefulness of the test in diagnosis. This awaits the results of further investigation. Nevertheless, from our limited data, it appeared worthwhile to use this test in patients with rheumatoid arthritis as in cases of rheumatic fever.

The similarly high agglutination titers of the sera from patients with rheumatic fever and from those with hemolytic streptococcus has pointed to a possible etiological association of hemolytic streptococcus with rheumatic fever. On the other hand, one might take this finding as analogous to the Weil-Felix reaction in rickettsial diseases. This seems less likely in view of the epidemiological evidence of an association between streptococcal infections and rheumatic fever. Whether a similar interpretation can be applied to rheumatoid arthritis is beyond the scope of the present study. One may still wonder whether similarly high agglutination titers would be obtained with other autoclaved organisms, particularly other Gram positive or negative cocci. As mentioned above in the fourth group of sera examined, nine out of 11 samples of serum obtained from patients 
with lobar pneumonia failed to agglutinate the autoclaved streptococci. This offered evidence for the specificity of this particular agglutination reaction. The denaturation of protein by heat has probably left the somatic polysaccharide alone among the known factors to be considered of any consequence in serving as the antigenic fraction responsible for the agglutination reaction. Further studies on the specificity of this reaction and the possible part played by the group-specific polysaccharide have been reported elsewhere (10).

\section{SUM MARY}

An agglutination reaction using autoclaved (120 $\mathrm{C}$ for two hours) hemolytic streptococci has been described and investigated. It has been used in this study with samples of serum from patients with rheumatic fever, rheumatoid arthritis, and streptococcal diseases, as well as with other conditions.

The agglutination titers in groups of patients with rheumatic fever, rheumatoid arthritis, and streptococcal diseases did not differ significantly one from the other. The titers in each of these conditions were significantly higher than in the control groups.

\section{ACKNOWLEDGMENTS}

Thanks must be due to Dr. Robert W. Quinn, who kindly provided the human sera used in this investigation, and to Dr. Edward C. Curnen, Jr., for his invaluable criticisms about this study. The writer wishes also to express his gratitude particularly to Prof. John R.
Paul for his guidance and counsel in the present investigation.

\section{BIBLIOGRAPHY}

1. Thulin, K. E., On the presence of O-agglutinins against streptococci in cases of rheumatoid arthritis and rheumatic fever. Abstracts of communications. Fourth International Congress for Microbiology. Copenhagen, 1947, p. 49.

2. Thulin, K. E., Proceedings of Svenska foreningens for invartes medicin. Nord. Med., 1947, 33, 508.

3. Thulin, K. E., Serological aspects of hemolytic streptococci, with special reference to the occurrence of $\mathrm{O}, \mathrm{K}$, and $\mathrm{L}$ antigens, and some clinical applications. Acta path. et microbiol. Scandinav., Suppl. 75, 1948.

4. Thulin, K. E., and Valhne, G., Investigation into the serology of beta-hemolytic streptococci. Acta path. et microbiol. Scandinav., 1946, 23, 484.

5. Brown, H. C., Further observations on the standardization of bacterial suspensions. Indian J. M. Research, 1919, 7, 238.

6. Cunningham, J., and Timothy, B., A comparison between the numerical content of certain bacterial suspensions obtained by the hemocytometer method and Brown's opacity tubes. Ibid., 1924, 11, 1253.

7. Clawson, B. J., Wetherby, M., Hilbert, E. H., and Hilleboe, H. E., Streptococcic agglutination in chronic arthritis and acute rheumatic fever. Am. J. M. Sc., 1932, 184, 758.

8. Goldie, W., The hemolytic streptococcus in the etiology of rheumatic fever and rheumatoid arthritis. Lancet, 1938, 2, 246.

9. Goldie, W., and Griffiths, G. J., Etiological relation of the Streptococcus hemolyticus to the "rheumatic" diseases. Brit. M. J., 1936, 2, 755.

10. Liao, S. J., The specificity of the agglutination reaction with autoclaved hemolytic streptococci and the role of the group-specific polysaccharide in the reaction. J. Immunol. (in press). 